\title{
Resveratrol reduces lipid peroxidation and increases sirtuin 1 expression in adult animals programed by neonatal protein restriction
}

\author{
Juliana Gastão Franco' ${ }^{1}$, Egberto Gaspar de Moura ${ }^{1}$, Josely Correa Koury ${ }^{2}$, Paula Affonso Trotta ${ }^{1}$, \\ Aline Cordeiro ${ }^{3}$, Luana Lopes Souza ${ }^{3}$, Norma Aparecida dos Santos Almeida ${ }^{3}$, Natália da Silva Lima ${ }^{1}$, \\ Carmen Cabanelas Pazos-Moura ${ }^{3}$, Patrícia Cristina Lisboa ${ }^{1}$ and Magna Cottini Fonseca Passos ${ }^{1,4}$ \\ ${ }^{1}$ Department of Physiological Sciences, Roberto Alcântara Gomes Biology Institute and ${ }^{2}$ Department of Basic and Experimental Nutrition, Institute of Nutrition, \\ State University of Rio de Janeiro, Rio de Janeiro 20550-030, RJ, Brazil \\ ${ }^{3}$ Laboratory of Molecular Endocrinology, Institute of Biophysics Carlos Chagas Filho, Federal University of Rio de Janeiro, Rio de Janeiro 21949-900, RJ, Brazil \\ ${ }^{4}$ Department of Applied Nutrition, Institute of Nutrition, State University of Rio de Janeiro, Rio de Janeiro 20550-013, RJ, Brazil \\ (Correspondence should be addressed to E G de Moura who is now at Departamento de Ciências Fisiológicas, Instituto de Biologia, Universidade do Estado do \\ Rio de Janeiro, $5^{\circ}$ andar, Avenue 28 de Setembro, 87, Rio de Janeiro 20550-030, RJ, Brazil; Email: egberto@pq.cnpq.br)
}

\begin{abstract}
Resveratrol (Res) has been associated with protective effects against oxidative stress. This study evaluated the effect of Res over lipid peroxidation, antioxidant defense, hepatic sirtuin 1 (SIRT1), which up-regulates antioxidant enzymes, and copper/zinc superoxide dismutase $(\mathrm{Cu} / \mathrm{Zn} \mathrm{SOD})$ in adult offspring whose mothers were protein restricted during lactation. Lactating Wistar rats were divided into control (C) group, which were fed a normal diet $(23 \%$ protein), and low-protein and high-carbohydrate (LPHC) group, which were fed a diet containing $8 \%$ protein. After weaning (21 days), $\mathrm{C}$ and LPHC offspring were fed a normal diet until they were 180 days old. At the 160th day, animals were separated into four groups as follows: control, control+Res, LPHC, and LPHC+Res. Resveratrol was given for 20 days ( $30 \mathrm{mg} / \mathrm{kg}$ per day by gavage). LPHC animals showed a higher total antioxidant capacity (TAC)
\end{abstract}

without change in lipid peroxidation and SIRT1 expression. The treatment with Res increased TAC only in the control group without effect on lipid peroxidation and SIRT1. LPHC animals treated with Res had lower lipid peroxidation and higher protein and mRNA expression of SIRT1 without any further increase in TAC. No significant difference in liver $\mathrm{Cu} / \mathrm{Zn} \mathrm{SOD}$ expression was observed among the groups. In conclusion, maternal protein restriction during lactation programs the offspring for a higher antioxidant capacity, and these animals seem to respond to Res treatment with a lower lipid peroxidation and higher hepatic SIRT1 expression that we did not observe in the Res-treated controls. It is probable that the protective effect can be attributed to Res activating SIRT1, only in the LPHC-programed group.

Journal of Endocrinology (2010) 207, 319-328

\section{Introduction}

Environmental, nutritional, or hormonal influences in early life (gestation and lactation) may change some physiological parameters in adulthood, a phenomenon known as programing (Lucas 1994, Barker 2007, Moura \& Passos 2005, Moura et al. 2008). Studies in human and animal models have shown that malnutrition during critical periods of neonatal life is associated with later metabolic disorders (Holness et al. 2000, Passos et al. 2000, 2004, Sichieri et al. 2000, Vicente et al. 2004). In developing countries, previously malnourished populations can afford a normal protein and energy supply in their diets during developmental periods and are at higher risk of developing diseases, according to developmental origins of disease hypothesis. Oxidative stress is implicated in most human diseases. Antioxidants may decrease the oxidative damage and its alleged harmful effects. Many people take antioxidant supplements, such as resveratrol, believing them to improve their health and prevent diseases (Balluz et al. 2000, Radimer et al. 2004, Glauert et al. 2010).

Previously, we demonstrated in rats that a low-protein and high-carbohydrate (LPHC) diet during lactation programs for lower body weight, lower visceral and total fat mass, lower glycemia and insulinemia, and leptin resistance at adulthood (Passos et al. 2004, Fagundes et al. 2007, 2009). Other studies reported a lower insulin secretion and higher insulin sensitivity in adult rats submitted to severe postnatal protein restriction (0 or 4\% protein content; Moura et al. 1997) and increased insulin sensitivity in adult rats whose mothers were fed a diet containing $10 \%$ protein during lactation (Zambrano et al. 2006). Furthermore, offspring of dams fed a low-protein diet during lactation had higher levels of sirtuin 1 (SIRT1) at 12 weeks of age that may regulate the aging process (Chen et al. 2009a). Protein restriction in lactation has been associated with nephroprotective effects in adult male rats and increased antioxidant expression (Tarry-Adkins et al. 2007). 
It is widely accepted that chronic energy restriction (ER) can increase longevity in many organisms from yeast to mammals and delays the onset of several age-related diseases in rodents (McCay et al. 1935, Barja 2000, Gredilla \& Barja 2005) associated with an increase of SIRT1, a histone deacetylase (Bordone \& Guarente 2004). However, the mechanisms through which chronic ER results in longevity and robust health are still unclear. In recent years, it has been shown that long-term ER decreases the levels of oxidative damage to cellular macromolecules mainly by reducing the rate of mitochondrial reactive oxygen species (ROS) generation in rodents (Gredilla \& Barja 2005). In contrast to chronic ER, studies in rats showed that maternal ER, during lactation only, programs the adult offspring to a higher body length and weight (Passos et al. 2004, Vicente et al. 2004), while maternal protein restriction seems to protect against obesity and insulin resistance (Fagundes et al. 2007, 2009).

Early-life nutrition also seems to influence longevity in rodents since protein restriction and slow growth during lactation lead to early-life alterations in the expression of key molecules, such as SIRT, which may influence lifespan (Chen et al. 2009a,b). The dietary factor that may be responsible for part of the longevity extension effect occurring in chronic ER is the restriction of the specific amino acid methionine. Studies have shown that methionine restriction can decrease mitochondrial ROS production and oxidative stress (Caro et al. 2009a). Restriction of dietary amino acids other than methionine decreases mitochondrial protein oxidation and increases SIRT1 in rat liver (Caro et al. 2009b).

Cells are equipped with enzymatic and non-enzymatic antioxidant systems to eliminate ROS. Enzymatic antioxidant defenses involve a group of enzymes, such as superoxide dismutase (SOD) that converts accumulated anion superoxide $\left(\mathrm{O}_{2}^{-}\right)$to $\mathrm{H}_{2} \mathrm{O}_{2}$. $\mathrm{Cu} / \mathrm{Zn} \mathrm{SOD}$ (SOD1) is one of the major isoforms of SOD. Non-enzymatic antioxidants are represented by ascorbic acid (vitamin C), $\boldsymbol{\alpha}$-tocopherol (vitamin E), glutathione (GSH), carotenoids, flavonoids, hemoglobin, and other antioxidants (Yu 1994, Devaraj \& Jialal 2000, Shen et al. 2006).

Sirtuins are a family of class III histone/protein deacetylases. In mammals, seven homologues (SIRT1-SIRT7) have been identified and SIRT1 is a central factor in the metabolic adaptation to ER, triggering appropriate physiological responses via the modulation of the activity of key transcriptional factors involved in metabolism and oxidative stress (Bordone \& Guarente 2004).

Resveratrol (Res, trans-3, $4^{\prime}, 5$-trihydroxystilbene), a natural phytoalexin found in grapes, mimics the positive effects of chronic ER. Res is recognized for its wide range of biological effects, including anti-inflammatory, anticancer, and antimutagenic protection from atherosclerotic disease (Howitz et al. 2003, Baur et al. 2006). The effects of Res are mediated in part by its ability to activate SIRT1 (Lagouge et al. 2006). Studies have shown that Res can extend the lifespan of Saccharomyces cerevisiae (Howitz et al. 2003, Jarolim et al. 2004),
Caenorhabditis elegans (Wood et al. 2004, Viswanathan et al. 2005), Drosophila melanogaster (Bauer et al. 2004), and the vertebrate fish Nothobranchius furzeri (Valenzano et al. 2006). However, in rodents, Res can delay age-related deterioration in mice without extending lifespan (Pearson et al. 2008).

As mentioned before, adult rats programed by low-protein diets during lactation presented a favorable metabolic phenotype, with lower adiposity and higher insulin sensitivity. We hypothesized that this phenotype may also be associated with lower oxidative stress and a better response to the anti-oxidative effects of resveratrol, together with a higher expression of SIRT1. Thus, our aim was to evaluate the effect of Res on lipid peroxidation, antioxidant defense, and the expression of SIRT1 in the liver of both adult controls and LPHC-programed animals.

\section{Materials and Methods}

\section{Experimental model}

Wistar rats were kept in a temperature-controlled room $\left(25 \pm 1{ }^{\circ} \mathrm{C}\right)$ with artificial dark-light cycles (lights on $0700 \mathrm{~h}$, lights off $1900 \mathrm{~h}$ ). Adult female rats were caged with male rats at the proportion of 3:1. After mating, each female was placed in an individual cage with free access to water and food until delivery. Our experimental design was approved by the Animal Care and Use Committee of the Biology Institute of the State University of Rio de Janeiro (CEA/189/2007), which based their analysis on the principles adopted and promulgated by the Brazilian Law issued on November 8 , 2008, which concerns the rearing and use of animals in teaching and research activities in Brazil (Marques et al. 2009).

At birth, 16 lactating rats were randomly assigned to each one of the following groups: control $(\mathrm{C} ; n=8)$ group, with free access to a standard laboratory diet (17\% protein); LPHC diet $(n=8)$ group, with free access to an isoenergetic and protein-restricted diet (8\%). Table 1 shows the composition of the diets, which follow recommended standards (Reeves $e t$ al. 1993). The LPHC and control diets were made in our laboratory using casein as the protein source. In order to make isoenergetic diets, a higher amount of starch was added to

Table 1 Composition of the control and low-protein diets $(\mathrm{g} / \mathrm{kg})$

\begin{tabular}{|c|c|c|}
\hline Ingredients & $\begin{array}{l}\text { Control } \\
\text { (17\% protein) }\end{array}$ & $\begin{array}{l}\text { LPHC } \\
\text { (8\% protein) }\end{array}$ \\
\hline Casein (85 g protein/100 g) & 200 & $94 \cdot 1$ \\
\hline Corn starch & 529 & 635 \\
\hline Sucrose & 100 & 100 \\
\hline Soybean oil & 70 & 70 \\
\hline Cellulose & 50 & 50 \\
\hline Choline bitartrate & $2 \cdot 5$ & $2 \cdot 5$ \\
\hline L-Cystine & 3 & 3 \\
\hline Mineral mix ${ }^{a}$ & 35 & 35 \\
\hline Vitamin mix $^{a}$ & 10 & 10 \\
\hline
\end{tabular}

${ }^{\mathrm{a}}$ Detailed composition is given by Reeves et al. 
the LPHC diet so as to make up for the decrease in energy content due to protein reduction (Fagundes et al. 2007). To avoid the influence of litter size on the programing effect, only mothers whose litter size was 10-12 offspring were used. At birth, all litters were adjusted to six males to each dam to maximize lactation performance. The diets started at birth, which was defined as day $0(\mathrm{~d} 0)$ of lactation, and ended at weaning (d21).

After weaning (21 days lactation), all pups received the standard laboratory diet until they were 180 days old. The body weight of pups was monitored daily, during lactation. From weaning until day 180, body weight and food intake were monitored every 4 days.

Three pups from each litter were randomly chosen and followed during the experimental period. On day 160, one male offspring from each of the eight litters was randomly assigned to receive resveratrol or vehicle solution, whereas the other animals of this litter were discarded. Both treatments were administered by gavage during an experimental period of 20 days. In group I, control (C) rats received $0.5 \%(\mathrm{w} / \mathrm{v})$ aqueous methylcellulose (vehicle); in group II, control + resveratrol $(\mathrm{C}+\mathrm{Res})$ rats received Res $(30 \mathrm{mg} / \mathrm{kg}$ per day); in group III, LPHC diet rats received $0 \cdot 5 \%(\mathrm{w} / \mathrm{v})$ aqueous methylcellulose; and in group IV, LPHC + Res rats received $30 \mathrm{mg} / \mathrm{kg}$ per day of resveratrol (Macarulla et al. 2009). Because of its low solubility in water, resveratrol was suspended in carboxymethylcellulose solution (Das et al. 2008). The suspension was prepared freshly and shaken vigorously before oral gavage. The amount used corresponded approximately to five times the amount consumed by a person who drinks $300 \mathrm{ml}$ of red wine a day containing $2 \cdot 0 \mathrm{mg}$ of trans-resveratrol, a dose that is not harmful to rats (Juan et al. 2002).

At the end of the experimental period, the rats were killed with a lethal dose of pentobarbital $(0.06 \mathrm{~g} / \mathrm{kg}$ body weight) in order to collect blood, liver, and visceral fat mass (VFM). The blood was collected by cardiac puncture and poured in a tube containing EDTA. VFM was excised and weighed for evaluation of the central adiposity - mesenteric, epididymal, and retroperitoneal. Plasma samples were frozen at $-80^{\circ} \mathrm{C}$ until analysis, and samples of liver and lipid tissues were frozen in liquid nitrogen and stored at $-70^{\circ} \mathrm{C}$.

\section{Glucose measurement}

Glycemia was determined in blood samples from the tail vein of fasting rats using a glucometer (ACCU-CHEK Advantage, Roche Diagnostics).

\section{Serum insulin determination}

Blood samples were centrifuged $\left(2000 \boldsymbol{g}\right.$ for $20 \mathrm{~min}$ at $\left.4{ }^{\circ} \mathrm{C}\right)$ to obtain serum, which was individually kept at $-20^{\circ} \mathrm{C}$ until assay. All measurements were performed in one assay. Insulin was determined by a commercial RIA kit (ImmuChem TM 125 I, coated tube, ICN Biomedicals, Inc., New York, NY, USA). The intra-assay variation was $8 \cdot 9 \%$.

\section{Insulin sensitivity evaluation}

We evaluated insulin sensitivity according to three formulas:

- I/G ratio: fasting insulin $(\mu \mathrm{UI} / \mathrm{ml}) /$ fasting glucose ( $\mathrm{mmol} / \mathrm{l})$

- The homeostasis model assessment of insulin resistance (HOMA-IR): (insulin $(\mu \mathrm{IU} / \mathrm{ml}) \times$ serum glucose $(\mathrm{mmol} / \mathrm{l})) / 22 \cdot 5$ (Matthews et al. 1985).

- HOMA- $\beta$ : (insulin $(\mu \mathrm{IU} / \mathrm{ml}) \times 20) /$ serum glucose (mmol/l) -3.5 (Matthews et al. 1985).

\section{Lipid profile}

Serum levels of total cholesterol, triglycerides, high-density lipoprotein (HDL-c), low-density lipoprotein (LDL-c), and very low-density lipoprotein (VLDL-c) were analyzed using Biosystem commercial test kits. LDL-c and VLDL-c were obtained using Friedewald calculations:

1) LDL-c $(\mathrm{mg} / \mathrm{dl})=$ total cholesterol $-($ triglycerides $/ 5)-$ HDL-c

2) $\operatorname{VLDL}-\mathrm{c}(\mathrm{mg} / \mathrm{dl})=$ triglycerides $/ 5$

\section{SIRT1 and $\mathrm{Cu} / \mathrm{Zn}$ SOD protein expression: western blotting analysis}

Hepatic tissues were excised and homogenized in an Ultra-Turrax T25 basic (IKA Werke GmbH \& Co. KG, Staufen, Germany) in lysis buffer (50 mM HEPES, $1 \mathrm{mM}$ $\mathrm{MgCl}_{2}, 10 \mathrm{mM}$ EDTA, and $1 \%$ Triton X-100 with the protease inhibitor cocktail Complete (Roche; $\mathrm{pH} 6 \cdot 4)$ ). After centrifugation, the homogenates were stored at $-20{ }^{\circ} \mathrm{C}$. SIRT1 and SOD1 content was analyzed by western blotting as described below.

The protein concentration was determined by the BCA protein assay kit (Pierce, Rockford, IL, USA). Samples (30 $\mu \mathrm{g}$ total protein) were electrophoresed in 12 or $12 \cdot 5 \%$ Tris-glycine SDS polyacrylamide gels. Proteins were transferred onto polyvinylidene fluoride membranes (Hybond ECL; Amersham Pharmacia Biotech), blocked in 5\% dry milk in T-TBS $(0.02 \mathrm{M}$ Tris $/ 0.15 \mathrm{M} \mathrm{NaCl}, \mathrm{pH} 7 \cdot 5$, containing $0 \cdot 1 \%$ Tween 20 ) at room temperature for $1 \mathrm{~h}$, washed $3 \times$ with T-TBS, and incubated with the primary antibodies $(\mathrm{Cu} / \mathrm{Zn}$ SOD, 1:500; SIRT1, 1:500) for $1 \mathrm{~h}$ at room temperature. $\mathrm{Cu} / \mathrm{Zn}$ SOD and SIRT1 antibodies were purchased from Santa Cruz Biotechnology, Inc. (San Francisco, CA, USA). After washing $3 \times$ with T-TBS, the blots were incubated with secondary antibodies (SIRT1 1:6250, peroxidase-labeled anti-rabbit IgG, Amersham Biosciences, Inc., and $\mathrm{Cu} / \mathrm{Zn} \mathrm{SOD}-1: 1000$, peroxidaselabeled anti-rabbit IgG, Santa Cruz Biotechnology) for $1 \mathrm{~h}$ and then incubated with streptavidin (Zymed, San Francisco, CA, USA) in the same dilution of the secondary antibody for $1 \mathrm{~h}$. The blots were then washed and developed with diaminobenzamidine (Sigma Chemical Co.) as a chromogenic substrate or with enhanced chemiluminescence 

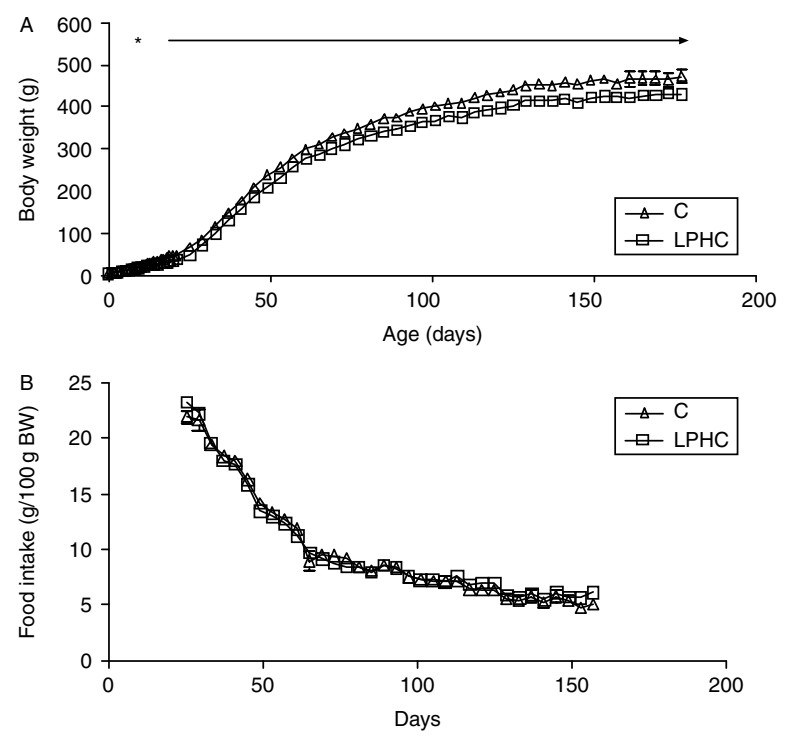

Figure 1 Body weight and relative food intake evolution. (A) Body weight of rats whose mothers were fed with $C$ (open triangle) or LPHC (open square) diet during lactation. (B) Food intake (g/100 g body weight) after weaning until adulthood of rats whose mothers were fed a C (open triangle) or LPHC (open square) diet during lactation. Data are reported as mean \pm S.E.M. Statistical significance was determined by two-way ANOVA and Newman-Keuls post-test. $* P<0 \cdot 05 ; n=8$ animals/group.

(Amersham Biosciences, Inc.). The SIRT1 membranes were stained with rouge ponceau to evaluate the relative amounts of transferred proteins (Almeida et al. 2009).

\section{SIRT1 RNA expression: reverse transcription-PCR analysis}

Total RNA was isolated from hepatic tissue using commercially available and standard methodology (TRIZOL reagent, Invitrogen) respectively. For quantitative real-time reverse transcription PCR (real-time RT-PCR) analysis, RT was carried out on $1 \mu \mathrm{g}$ of total RNA for all tissues using SuperScript III kit. The products were amplified on Applied Biosystems 7500 Real-Time PCR System (Life Technologies Co.) using SYBR Green PCR Master Mix (Applied BioSystems, Foster City, CA, USA) according to the recommendations of the manufacturer. Briefly, after initial denaturation at $50{ }^{\circ} \mathrm{C}$ for $2 \mathrm{~min}$ and at $95^{\circ} \mathrm{C}$ for $10 \mathrm{~min}$, reactions were cycled 40 times using the following parameters: $95{ }^{\circ} \mathrm{C}$ for $15 \mathrm{~s}, 60{ }^{\circ} \mathrm{C}$ for $30 \mathrm{~s}$, and $70{ }^{\circ} \mathrm{C}$ for $45 \mathrm{~s}$. Product purity was confirmed by agarose gel analysis. Relative mRNA levels were determined by comparing the PCR cycle threshold $\left(C_{t}\right)$ between groups. The housekeeping gene used was 36B4. Data are expressed as fold induction over the control group, which was set to 1 or $100 \%$. The sequences of the forward and reverse primers were respectively $5^{\prime}$-CAGGTPGCAGGAATCCAAA- $3^{\prime}$ and $5^{\prime}$-CAAATCAGGCAAGATGCTGT- $3^{\prime}$ for Sirt1 and $5^{\prime}$-CCGAGGCAACAGTTGGGTA-3' for 36B4 (Rodgers et al. 2005, Machado et al. 2009).

\section{Thiobarbituric acid-reactive substances}

As an index of lipid peroxidation, we used the formation of thiobarbituric acid-reactive substances (TBARS) during an acid-heating reaction as previously described (Draper et al. 1993). Briefly, plasma was mixed with $1 \mathrm{ml}$ of $10 \%$ trichloroacetic acid and $1 \mathrm{ml}$ of $0.67 \%$ thiobarbituric acid (Sigma Chemical Co.); subsequently, they were heated in a boiling water bath for $30 \mathrm{~min}$. TBARS were determined by the absorbance at $532 \mathrm{~nm}$ in a spectrophotometer and were expressed as malondialdehyde (MDA) equivalents $(\mathrm{nm} / \mathrm{ml})$.

\section{Total antioxidant capacity}

Total antioxidant capacity (TAC) was evaluated by measuring the reduction of 1,1-diphenyl-2-picrylhydrazyl (DPPH) stable-free radical by blood plasma. The DPPH reduction assay was performed by adding a sample $(20 \mu \mathrm{l}$ of blood plasma) plus $10 \mathrm{mM}$ sodium phosphate buffer, $\mathrm{pH} 7 \cdot 4$ (total volume of $400 \mu \mathrm{l}$ ), to $400 \mu \mathrm{l}$ of $0 \cdot 1 \mathrm{mM}$ methanol solution of DPPH. After $30 \mathrm{~min}$ incubation at ambient temperature
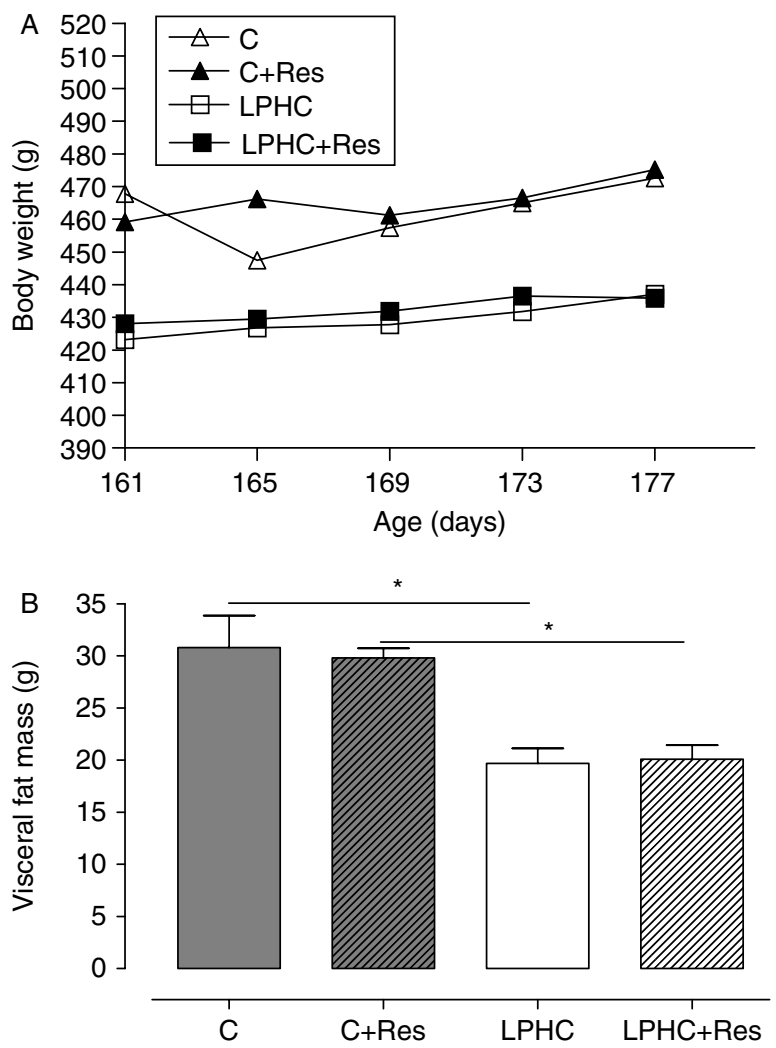

Figure 2 Body weight evolution during the treatment with Res and visceral fat mass in 180-day-old rats. (A) Body weight from 160 to 180 days of age of control rats that received Res (filled triangle) or vehicle (open triangle) and of LPHC rats that received Res (closed square) or vehicle (open square). (B) Visceral fat mass of control, $\mathrm{LPHC}, \mathrm{C}+$ Res, and LPHC + Res rats. Data are reported as mean \pm s.E.M. Statistical significance was determined by two-way ANOVA and Newman-Keuls post-test. ${ }^{*} P<0 \cdot 05 ; n=8$ animals/group. 
$\left(21^{\circ} \mathrm{C}\right)$, absorbance of the samples at $520 \mathrm{~nm}$ was measured and compared with that of a reference sample containing only DPPH solution and phosphate buffer (Janaszewska \& Bartosz 2002).

\section{Statistical analysis}

Results are reported as mean \pm s.E.M. Differences between the $\mathrm{C}$ and LPHC groups were analyzed by two-way ANOVA followed by Newman-Keuls post-test. Differences were considered significant at $P<0 \cdot 05$.

\section{Results}

Body weight and relative food intake from weaning (21 days) to the killing (180 days) are shown in Fig. 1. Offspring from mothers fed a LPHC diet had lower body weight from the 11 th day of lactation until adulthood (Fig. 1A), but no change in food intake (Fig. 1B). Resveratrol, administered by gavage during 20 days to 160 - to 180 -day-old rats, did not alter their body weight (Fig. 2A). LPHC offspring showed lower VFM at 180 days of age $(-36 \%, P<0 \cdot 05)$. Oral administration of Res did not alter VFM either in control group or in LPHC group (Fig. 2B).

As shown in Table 2, LPHC group presented lower glycemia $(-11 \%, P<0.05)$ in 180 -day-old rats. The treatment with resveratrol did not modify glucose serum concentration in any group. Insulinemia was lower in the LPHC group $(-36 \%$ versus $\mathrm{C}, P<0 \cdot 05)$ and in the $\mathrm{LPHC}+$ Res group $(-28 \cdot 3 \%$ versus $C+$ Res, $P<0 \cdot 05)$. Concerning insulin sensitivity, LPHC animals presented lower ratio insulin/glycemia $(-33 \%$ versus C, $P<0 \cdot 05)$, lower HOMA-IR $(-47 \%$ versus $C, P<0 \cdot 05)$, and lower HOMA- $\beta(-32 \%$ versus $C, P<0 \cdot 05)$, and resveratrol did not alter this profile in these rats.
Lower total cholesterol was observed in LPHC animals $(-19 \%, P<0 \cdot 05$; Table 2$)$. The Res treatment did not alter the serum lipid profile in any group.

Figure 3 shows lipid peroxidation, evaluated by plasma TBARS measurement. Rats whose mothers were fed with LPHC diet during lactation showed no difference in plasma TBARS concentration. Res induced a significant reduction of plasma TBARS only in LPHC group $(-48 \%$ versus LPHC, $-52 \%$ versus $C ; P<0 \cdot 01$ and $-41 \%$ versus $C+$ Res; $P<0 \cdot 01$, Fig. 3A).

As shown in Fig. 3B, the adult progeny from LPHC mothers had a higher TAC when compared with that from $\mathrm{C}$ mothers $(+25 \%, P<0 \cdot 05)$. Res administration induced a significant increase of TAC only in the control group $(+16 \%, P<0 \cdot 05)$.

Hepatic protein and mRNA expression of SIRT1 and protein expression of $\mathrm{Cu} / \mathrm{Zn}$ SOD are shown in Fig. 4. Res treatment only increased hepatic SIRT1 protein in the LPHC group $(+10 \%, P<0 \cdot 05$, Fig. $4 \mathrm{~A})$, and the increase in mRNA expression was more evident $(3 \cdot 5$-fold versus LPHC, $P<0 \cdot 05$, Fig. 4B).

No significant difference in $\mathrm{Cu} / \mathrm{Zn}$ SOD expression was observed among the groups (Fig. 4C).

\section{Discussion}

The main focus of our present study was to evaluate the effect of resveratrol over the oxidative stress and the expression of SIRT1 in the liver both in control and in animals programed by a LPHC diet during lactation. The present findings indicate that maternal protein restriction during lactation programed the adult offspring for a higher TAC than controls, which was not further incremented by resveratrol. However, resveratrol was able to decrease lipid peroxidation only in the LPHC-programed animals, and this effect may be related to an increase of SIRT1 in the liver. To the best of our

Table 2 Glucose homeostasis and serum lipid profile of 180-day-old offspring whose mothers were fed with a normal diet during lactation and treated with Res (C+Res) or vehicle $(C)$ and in offspring whose mothers were fed with a low-protein and high-carbohydrate (LPHC) diet during lactation and treated with Res (LPHC+Res) or vehicle (LPHC)

Glycemia $(\mathrm{mg} / \mathrm{dl})$
Serum insulin $(\mu \mathrm{Ul} / \mathrm{ml})$
I/G ratio
HOMA-IR
HOMA- $\beta$
Total cholesterol $(\mathrm{mg} / \mathrm{dl})$
HDL-c $(\mathrm{mg} / \mathrm{dl})$
LDL-c $(\mathrm{mg} / \mathrm{dl})$
VLDL-c $(\mathrm{mg} / \mathrm{dl})$
Triglycerides $(\mathrm{mg} / \mathrm{dl})$

C

$76 \cdot 5 \pm 1 \cdot 6$
$57 \cdot 2 \pm 2 \cdot 9$
$13 \cdot 4 \pm 1 \cdot 0$
$10 \cdot 9 \pm 1 \cdot 2$
$264 \cdot 6 \pm 20$
$71 \cdot 3 \pm 4 \cdot 4$
$30 \cdot 3 \pm 1 \cdot 5$
$23 \cdot 7 \pm 3 \cdot 5$
$11 \cdot 9 \pm 1 \cdot 2$
$59 \cdot 2 \pm 6 \cdot 1$

\begin{tabular}{l} 
C+Res \\
\hline $71 \cdot 5 \pm 1 \cdot 7$ \\
$53 \cdot 1 \pm 3 \cdot 4$ \\
$12 \cdot 1 \pm 0 \cdot 8$ \\
$9 \cdot 0 \pm 0 \cdot 5$ \\
$238 \cdot 9 \pm 16$ \\
$61 \cdot 4 \pm 3 \cdot 3$ \\
$31 \cdot 5 \pm 1 \cdot 4$ \\
$22 \cdot 6 \pm 2 \cdot 7$ \\
$9 \cdot 9 \pm 0 \cdot 7$ \\
$44 \cdot 5 \pm 4$
\end{tabular}

LPHC

$68 \cdot 2 \pm 2 \cdot 7^{*}$
$36 \cdot 6 \pm 4 \cdot 6^{*}$
$9 \cdot 0 \pm 1 \cdot 2^{*}$
$5 \cdot 8 \pm 0 \cdot 9^{*}$
$177 \cdot 9 \pm 24^{*}$
$57 \cdot 4 \pm 2 \cdot 6^{*}$
$26 \cdot 9 \pm 0 \cdot 6$
$24 \cdot 4 \pm 3 \cdot 2$
$9 \cdot 8 \pm 0 \cdot 7$
$51 \pm 4 \cdot 7$

LPHC + Res

$71 \cdot 4 \pm 1 \cdot 2$
$38 \cdot 0 \pm 3 \cdot 6^{*}$
$9 \cdot 6 \pm 0 \cdot 9^{*}$
$6 \cdot 7 \pm 0 \cdot 7^{*}$
$188 \cdot 6 \pm 18^{*}$
$64 \cdot 3 \pm 3 \cdot 7$
$30 \cdot 0 \pm 1 \cdot 2$
$23 \cdot 5 \pm 3 \cdot 9$
$10 \cdot 2 \pm 0 \cdot 9$
$45 \cdot 4 \pm 2 \cdot 6$


A
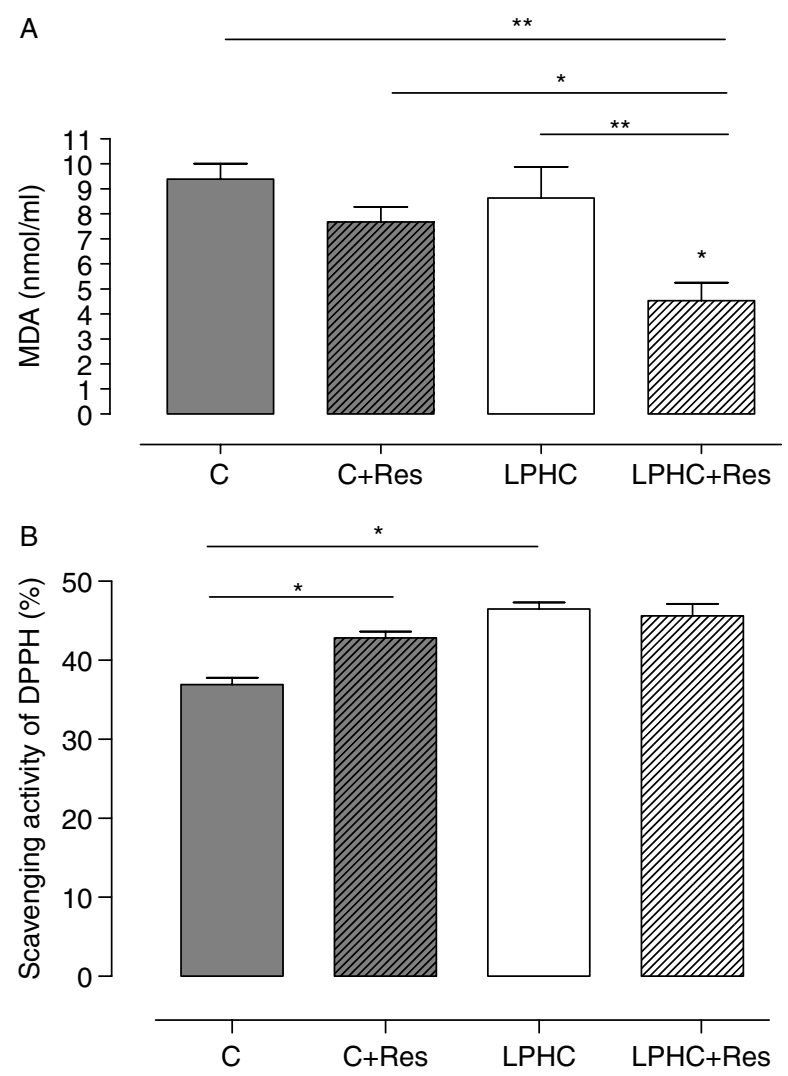

Figure 3 Plasma levels of thiobarbituric acid-reactive substances and total antioxidant capacity. (A) Plasma levels of TBARS at 180 days in offspring whose mothers were fed with a normal diet during lactation and treated with Res $(C+\operatorname{Res})$ or vehicle $(C)$ and in offspring whose mothers were fed with a LPHC diet during lactation and treated with Res (LPHC+Res) or vehicle (LPHC). (B) Scavenging activity of DPPH in plasma at 180 days of age of control, LPHC, C+Res, and LPHC + Res rats. Data are reported as mean \pm S.E.M. Statistical significance was determined by two-way ANOVA and Newman-Keuls post-test. ${ }^{*} P<0 \cdot 05$ and ${ }^{* *} P<0 \cdot 01$; $n=8$ animals/group.

knowledge, there are no data reporting the effect of resveratrol in the adult offspring programed by protein restriction during lactation. Resveratrol is usually ingested in wine. Thus, in our model, we chose an adult age to be compatible with the age of wine ingestion in humans, and the period of 20 days seems to be a chronic treatment in most rat studies. Besides wine, resveratrol is present in other food sources such as peanuts, and could be used as food supplements. Since protein malnutrition is still highly prevalent in human population and the use of antioxidants is increasingly recommended, the present result points that Res is more useful in previously protein-restricted individuals.

We confirmed our previous observations showing that maternal protein restriction during lactation programed the adult offspring for lower body weight and lower VFM (Passos et al. 2000, Fagundes et al. 2007, 2009). Since the food intake was similar among the groups, the lower adiposity suggests lower lipogenesis or higher lipolytic activity, probably caused by changes in key hormones, such as higher thyroid hormones, catecholamine, and glucocorticoid, which are previously reported in these animals (Dutra et al. 2003, Fagundes et al. 2007, 2009, Lisboa et al. 2008). Resveratrol did not affect VFM in either group, and there is no previous report on the effect of resveratrol on VFM.

In accordance with our previous report (Fagundes et al. 2009), LPHC animals had lower glycemia and insulinemia in 180-day-old rats. These findings, together with lower I/G ratio, HOMA-IR, and HOMA- $\beta$, indicate that these animals had higher insulin sensitivity. Resveratrol did not modify this profile in both LPHC and control groups. Thus, the antioxidant effect of resveratrol in LPHC does not seem to be consequent to glucose homeostasis improvement. The ability of resveratrol to reduce insulin levels and hyperglycemia was reported in several studies including streptozotocin- and nicotinamide-induced experimental diabetic rats (Palsamy \& Subramanian 2008, Ramadori et al. 2009, Sharma et al. 2010). However, these effects of resveratrol seemed to occur in animals that had impaired glucose homeostasis.

On day 180, LPHC offspring showed lower total cholesterol. This finding was in accordance with our previous study and may be associated with higher insulin sensitivity in liver or higher cholesterol biliary excretion caused by the higher serum thyroid hormones in these animals (Lisboa et al. 2008, Fagundes et al. 2009). Resveratrol did not alter serum lipid profile in any group. Although one study had demonstrated the ability of resveratrol to improve dyslipidemia in rodents (Mulvihill \& Huff 2010), this seems to be controversial because other studies in obese rats given a similar dose to that in our study for 8 weeks reported unaltered lipid profiles (Aubin et al. 2008, Rivera et al. 2009). Thus, similar to the unchanged glucose homeostasis, the better antioxidant effect in LPHC group cannot be associated with changes in lipid profile.

Non-enzymatic antioxidants present in plasma, such as glutathione, vitamin $\mathrm{C}$, vitamin $\mathrm{E}$, and bilirubin, detoxify ROS and minimize the damage caused to biomolecules. Studies have shown that the stable free radical DPPH could be a useful, simple, and inexpensive method of estimation of the TAC in biological samples (Chrzczanowicz et al. 2008, Botelho et al. 2010). The higher TAC found in LPHCprogramed animals is in agreement with previous studies showing that protein restriction during lactation induced an up-regulation of antioxidant defense capacity at adulthood, represented by increased expression of kidney antioxidant enzymes: glutathione peroxidase and glutathione reductase in 3-month-old rats and glutathione peroxidase, glutathione reductase, and manganese SOD in 1-year-old rodents (Tarry-Adkins et al. 2007, 2008, Chen et al. 2009a,b). On the other hand, other studies had associated protein restriction during neonatal life with increased oxidative stress and related detrimental effects (Fetoui et al. 2009, Theys et al. 2009). It has been shown that low-protein diets during gestation or gestation and lactation could predispose to pancreatic islet 
A

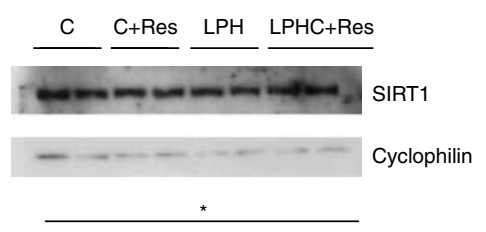

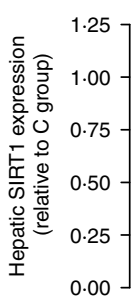

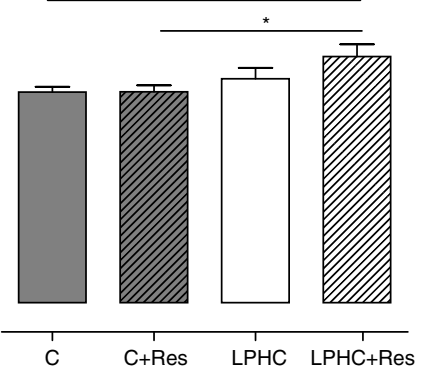

B

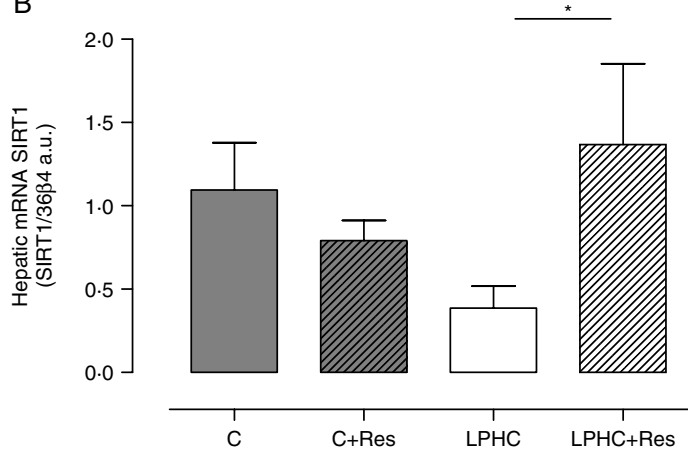

C

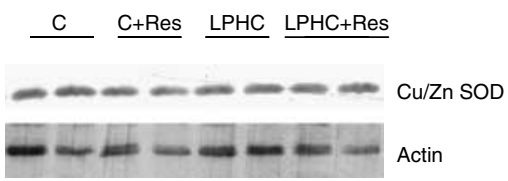

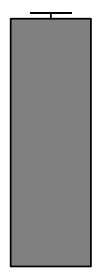

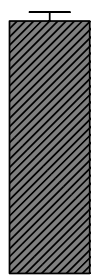

C+Res

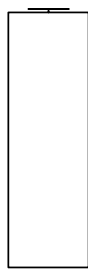

LPHC

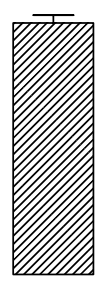

LPHC+Res

Figure 4 Hepatic protein and mRNA expression of SIRT1 and protein expression of $\mathrm{Cu} / \mathrm{Zn}$ SOD at 180 days in offspring whose mothers were fed with a normal diet during lactation and treated with Res $(\mathrm{C}+\mathrm{Res})$ or vehicle (C) and in offspring whose mothers were fed with a LPHC diet during lactation and treated with Res (LPHC + Res) or vehicle (LPHC). (A) Hepatic SIRT1 protein expression. (B) Hepatic mRNA SIRT1 expression. (C) Hepatic Cu/Zn SOD protein expression. Data are reported as mean \pm S.E.M. Statistical significance was determined by two-way ANOVA and Newman-Keuls post-test. ${ }^{*} P<0 \cdot 05 ; n=8$ animals/group.

dysfunction later in life by an imbalance between higher concentration of superoxide radical-inactivating enzymes (SOD) and very low concentration of hydrogen peroxideinactivating enzymes (CAT and GPX) in islets of the progeny in 3-month-old rats (Theys et al. 2009). In addition, proteinrestricted diet given to mothers during late pregnancy and early postnatal periods induced oxidative stress in their pups on postnatal d14 (Fetoui et al. 2009). These findings indicate that the time window of protein restriction seems to be of critical importance for modulation of antioxidant defense capacity in adult life.

In the present study, although TAC is higher in the LPHC group, no differences in the liver antioxidant enzyme $\mathrm{Cu} / \mathrm{Zn}$ SOD were observed among the groups. Ungvari et al. (2007) showed that resveratrol up-regulated the expression of other antioxidant enzymes such as glutathione peroxidase, catalase, and heme oxygenase- 1 in cultured arteries, whereas it had no significant effect on the expression of SOD isoforms.

Since epidemiological studies have shown an inverse relation between red wine consumption and incidence of cardiovascular disease, the compounds present in grapes, mainly resveratrol, have been of great interest to researchers (Frémont 2000). Resveratrol is rapidly absorbed and metabolized, mainly as sulfo- and glucuro-conjugates that are excreted in urine, and seems to be well tolerated and non-toxic both in humans and in rats (Juan et al. 2002, Williams et al. 2009, Cottart et al. 2010). Although studies have shown that plasma resveratrol concentration is low, raising doubts about its efficiency (Goldberg et al. 2003, Vitaglione et al. 2005). Soleas et al. (2001) suggests that resveratrol levels in plasma could be seriously underestimated since a large part of the molecule may be bound by cell membranes or lipophilic tissues. Here, we showed that oral administration of resveratrol increases TAC in the control group. It is interesting to note that resveratrol did not modify TAC in the LPHC group. Since this group has already high levels of TAC, it is possible that TAC reached a saturated level. However, lipid peroxidation, evaluated by plasma TBARS concentration, decreased only in the LPHC + Res group. Lipid peroxidation refers to the oxidative degradation of lipids whereby free radicals pick up electrons from the lipids in cell membranes, resulting in cell damage. TBARS assay is a simple and useful method to quantify the end products of lipid peroxidation, specifically MDA. A similar reduction in plasma TBARS concentration was observed in fructose-fed rats during chronic administration of resveratrol (Miatello et al. 2005). It is postulated that Res probably reduces the deleterious effect of oxidative stress in living cells due to its ability to 1) compete with co-enzyme $\mathrm{Q}$ and decrease mitochondrial ROS production, 2) scavenge superoxide radicals, 3) inhibit lipid peroxidation induced by Fenton reactions, and 4) regulate the expression of antioxidant co-factors and enzymes (Pervaiz \& Holme 2009). In addition, some studies demonstrated that Res inhibits NADPH oxidase activity and expression, which is a major contributor to 
superoxide radical production causing local oxidative stress (Soylemez et al. 2009, Spanier et al. 2009).

Along with a decrease in lipid peroxidation, resveratrol also induced a small but significant increase in protein and a higher increment (3.5-fold) in mRNA expression of SIRT1 in the liver only in the group programed by maternal protein restriction. This apparent discrepancy in the percentage of increment between protein and mRNA expression is due, at least in part, to the more variable values in mRNA expression and also by a higher post-translational metabolism of the protein during processing. Other authors have shown that resveratrol treatment caused a significant increase in SIRT1 expression in association with anti-oxidative and antiinflammatory effects in experimental models of colitis (Singh et al. 2010) and diabetic cardiomyopathy (Sulaiman et al. 2010). Moreover, the effect of resveratrol, attenuating the oxidative metabolism induced by high glucose on endothelial cells, was prevented by the ablation of SIRT1 expression (Ungvari et al. 2009). In addition, moderate overexpression of SIRT1 protected cells from oxidative stress (Csiszar et al. 2006, Alcendor et al. 2007, Lee et al. 2009), and hepatic SIRT1 action attenuated hepatic steatosis, inflammation, and oxidative stress (Purushotham et al. 2009). Therefore, it is likely the involvement of high liver SIRT1 in the reduction of lipid peroxidation in the LPHC+Res group. However, studies have shown that resveratrol is not a direct activator of SIRT1 since this compound interacts with multiple unrelated targets including receptors, enzymes, ion channels, and transporters (Beher et al. 2009, Pacholec et al. 2010).

It seems that to decrease lipid peroxidation, Res has to be acting in an animal with some increased level of nonenzymatic or enzymatic antioxidant capacity. Maybe the lower body weight present in these animals associated with lower adipogenesis (Fagundes et al. 2009) and higher insulin sensitivity are facilitating factors for resveratrol's protective effect against lipid peroxidation.

In conclusion, maternal protein restriction during lactation programs the adult offspring for a higher antioxidant capacity, and these animals seem to respond to treatment with resveratrol, which results in lower lipid peroxidation that may be mediated in part by increased liver SIRT1 expression.

\section{Declaration of interest}

The authors declare that there is no conflict of interest that could be perceived as prejudicing the impartiality of the research reported.

\section{Funding}

This research was supported by the 'National Council for Scientific and Technological Development' (Conselho Nacional de Desenvolvimento Científico e Tecnológico - CNPq), the "Carlos Chagas Filho Research Foundation of the State of Rio de Janeiro' (Fundação Carlos Chagas Filho de Amparo à Pesquisa do Estado do Rio de Janeiro - FAPERJ) and Coordination for the Enhancement of Higher Education Personnel (Coordenação de Aperfeiçoamento de Pessoal de Nível Superior - CAPES).

\section{Acknowledgements}

All authors are grateful to Ms Mônica Gaspar de Moura, Ms Luzia Miranda, Mr José Firmino Nogueira Neto, and Mr Carlos Roberto for their technical assistance.

\section{References}

Alcendor RR, Gao S, Zhai P, Zablocki D, Holle E, Yu X, Tian B, Wagner T, Vatner SF \& Sadoshima J 2007 Sirt1 regulates aging and resistance to oxidative stress in the heart. Circulation Research 100 1512-1521. (doi:10. 1161/01.RES.0000267723.65696.4a)

Almeida NA, Cordeiro A, Machado DS, Souza LL, Ortiga-Carvalho TM, Campos-de-Carvalho AC, Wondisford FE \& Pazos-Moura CC 2009 Connexin 40 messenger ribonucleic acid is positively regulated by thyroid hormone $(\mathrm{TH})$ acting in cardiac atria via the $\mathrm{TH}$ receptor. Endocrinology 150 546-554. (doi:10.1210/en.2008-0451)

Aubin MC, Lajoie C, Clément R, Gosselin H, Calderone A \& Perrault LP 2008 Female rats fed a high-fat diet were associated with vascular dysfunction and cardiac fibrosis in the absence of overt obesity and hyperlipidemia: therapeutic potential of resveratrol. Journal of Pharmacology and Experimental Therapentics 325 961-968. (doi:10.1124/jpet.107.135061)

Balluz LS, Kieszak SM, Philen RM \& Mulinare J 2000 Vitamin and mineral supplement use in the United States: results from the third National Health and Nutrition Examination Survey. Archives of Family Medicine 9 258-262. (doi:10.1001/archfami.9.3.258)

Barja G 2000 Aging in vertebrates and the effect of caloric restriction: a mitochondrial free radical production-DNA damage mechanism? Biological Reviews 79 235-251. (doi:10.1017/S1464793103006213)

Barker DJ 2007 The origins of the developmental theory. Journal of Internal Medicine 261 412-417. (doi:10.1111/j.1365-2796.2007.01809.x)

Bauer JH, Goupil S, Garber GB \& Helfand SL 2004 An accelerated assay for the identification of lifespan-extending interventions in Drosophila melanogaster. PNAS 101 12980-12985. (doi:10.1073/pnas.0403493101)

Baur JA, Pearson KJ, Price NL, Jamieson HA, Lerin C, Kalra A, Prabhu VV, Allard JS, Lopez-Lluch G, Lewis K et al. 2006 Resveratrol improves health and survival of mice on a high-calorie diet. Nature 444 337-342. (doi:10. 1038/nature05354)

Beher D, Wu J, Cumine S, Kim KW, Lu SC, Atangan L \& Wang M 2009 Resveratrol is not a direct activator of SIRT1 enzyme activity. Chemical Biology \& Drug Design 74 619-624. (doi:10.1111/j.1747-0285. 2009.00901.x)

Bordone L \& Guarente L 2004 Calorie restriction, SIRT1 and metabolism: understanding longevity. Nature Reviews. Molecular Cell Biology 6 298-305. (doi:10.1038/nrm1616)

Botelho PB, Fioratti CO, Abdalla DS, Bertolami MC \& Castro IA 2010 Classification of individuals with dyslipidaemia controlled by statins according to plasma biomarkers of oxidative stress using cluster analysis. British Journal of Nutrition 103 256-265. (doi:10.1017/ S0007114509991711)

Caro P, Gomez J, Sanchez I, Naudi A, Ayala V, López-Torres M, Pamplona R \& Barja G 2009a Forty percent methionine restriction decreases mitochondrial oxygen radical production and leak at complex I during forward electron flow and lowers oxidative damage to proteins and mitochondrial DNA in rat kidney and brain mitochondria. Rejuvenation Research 12 421-434. (doi:10.1089/rej.2009.0902)

Caro P, Gomez J, Sanchez I, Garcia R, López-Torres M, Naudí A, PorteroOtin M, Pamplona R \& Barja G 20096 Effect of 40\% restriction of dietary amino acids (except methionine) on mitochondrial oxidative stress and biogenesis, AIF and SIRT1 in rat liver. Biogerontology 10 579-592. (doi:10. 1007/s10522-008-9200-4)

Chen JH, Martin-Gronert MS, Tarry-Adkins J \& Ozanne SE 2009a Maternal protein restriction affects postnatal growth and the expression of key proteins involved in lifespan regulation in mice. PLoS ONE 4 e4950. (doi:10.1371/journal.pone.0004950) 
Chen JH, Tarry-Adkins JL, Heppolette CA, Palmer DB \& Ozanne SE $2009 b$ Early-life nutrition influences thymic growth in male mice that may be related to the regulation of longevity. Clinical Science 118 429-438. (doi:10. 1042/CS20090429)

Chrzczanowicz J, Gawron A, Zwolinska A, de Graft-Johnson J, Krajewski W, Krol M, Markowski J, Kostka T \& Nowak D 2008 Simple method for determining human serum 2,2-diphenyl-1-picryl-hydrazyl (DPPH) radical scavenging activity - possible application in clinical studies on dietary antioxidants. Clinical Chemistry and Laboratory Medicine 46 42-49. (doi:10. 1515/CCLM.2008.062)

Cottart CH, Nivet-Antoine V, Laguillier-Morizot C \& Beaudeux JL 2010 Resveratrol bioailability and toxicity in humans. Molecular Nutrition \& Food Research 54 7-16. (doi:10.1002/mnfr.200900437)

Csiszar A, Smith K, Labinskyy N, Orosz Z, Rivera A \& Ungvari Z 2006 Resveratrol attenuates TNF- $\alpha$-induced activation of coronary arterial endothelial cells: role of NF- $\mathrm{KB}$ inhibition. American Journal of Physiology. Heart and Circulatory Physiology 291 1694-1649. (doi:10.1152/ajpheart. 00340.2006)

Das S, Lin HS, Ho PC \& Ng KY 2008 The impact of aqueous solubility and dose on the pharmacokinetic profiles of resveratrol. Pharmacology Research 25 2593-2600. (doi:10.1007/s11095-008-9677-1)

Devaraj S \& Jialal I 2000 Antioxidants and vitamins to reduce cardiovascular disease. Current Atherosclerosis Reports 2 342-351. (doi:10.1007/s11883000-0069-1)

Draper HH, Squires EJ, Mahmoodi H, Wu J, Agarwal S \& Hadley M 1993 A comparative evaluation of thiobarbituric acid methods for the determination of malondialdehyde in biological materials. Free Radical Biology and Medicine 15 353-363. (doi:10.1016/0891-5849(93)90035-S)

Dutra SC, Passos MC, Lisboa PC, Santos RS, Cabanelas AP, Pazos-Moura CC \& Moura EG 2003 Liver deiodinase activity is increased in adult rats whose mothers were submitted to malnutrition during lactation. Hormone and Metabolic Research 35 268-270. (doi:10.1055/s-2003-39485)

Fagundes AT, Moura EG, Passos MC, Oliveira E, Toste FP, Bonomo IT, Trevenzoli IH, Garcia RM \& Lisboa PC 2007 Maternal low-protein diet during lactation programmes body composition and glucose homeostasis in the adult rat offspring. British Journal of Nutrition 98 922-928. (doi:10.1017/ S0007114507750924)

Fagundes AT, Moura EG, Passos MC, Santos-Silva AP, Oliveira E, Trevenzoli IH, Casimiro-Lopes G, Neto JFN \& Lisboa PC 2009 Temporal evaluation of body composition, glucose homeostasis and lipid profile of male rats programmed by maternal protein restriction during lactation. Hormone and Metabolic Research 41 1-8. (doi:10.1055/s-0029-1233457)

Fetoui H, Garoui M \& Zeghal N 2009 Protein restriction in pregnant- and lactating rats-induced oxidative stress and hypohomocysteinaemia in their offspring. Journal of Animal Physiology and Animal Nutrition 93 263-270. (doi:10.1111/j.1439-0396.2008.00812.x)

Frémont L 2000 Biological effects of resveratrol. Life Sciences 66 663-673. (doi:10.1016/S0024-3205(99)00410-5)

Glauert HP, Calfee-Mason K, Stemm DN, Tharappel JC \& Spear BT 2010 Dietary antioxidants in the prevention of hepatocarcinogenesis: a review. Molecular Nutrition \& Food Research 54 875-896. (doi:10.1002/mnfr.200900482)

Goldberg DM, Yan J \& Soleas GJ 2003 Absorption of three wine-related polyphenols in three different matrices by healthy subjects. Clinical Biochemistry 36 79-87. (doi:10.1016/S0009-9120(02)00397-1)

Gredilla R \& Barja G 2005 Minireview: the role of oxidative stress in relation to caloric restriction and longevity. Endocrinology 146 3713-3717. (doi:10. 1210/en.2005-0378)

Holness MJ, Langdown ML \& Sugden MC 2000 Early-life programming of susceptibility to dysregulation of glucose metabolism and the development of type 2 diabetes mellitus. Biochemical Journal 349 657-665.

Howitz KT, Bitterman KJ, Cohen HY, Lamming DW, Lavu S, Wood JG, Zipkin RE, Chung P, Kisielewski A, Zhang LL et al. 2003 Small molecule activators of sirtuins extend Saccharomyces cerevisiae lifespan. Nature $\mathbf{4 2 5}$ 191-196. (doi:10.1038/nature01960)

Janaszewska A \& Bartosz G 2002 Assay of total antioxidant capacity: comparison of four methods as applied to human blood plasma. Scandinavian Journal of Clinical and Laboratory Investigation 62 231-236. (doi:10.1080/003655102317475498)
Jarolim S, Millen J, Heeren G, Laun P, Goldfarb DS \& Breitenbach M 2004 A novel assay for replicative lifespan in Saccharomyces cerevisiae. FEMS Yeast Research 5 169-177. (doi:10.1016/j.femsyr.2004.06.015)

Juan ME, Vinardell MP \& Planas JM 2002 The daily oral administration of high doses of trans-resveratrol to rats for 28 days is not harmful. Journal of Nutrition 132 257-260.

Lagouge M, Argmann C, Gerhart-Hines Z, Meziane H, Lerin C, Daussin F, Messadeq N, Milne J, Lambert P, Elliott P et al. 2006 Resveratrol improves mitochondrial function and protects against metabolic disease by activating SIRT1 and PGC-1 $\alpha$. Cell 127 1109-1122. (doi:10.1016/j.cell. 2006.11.013)

Lee MJ, Feliers D, Sataranatarajan K, Mariappan MM, Li M, Barnes JL, Choudhury GG \& Kasinath BS 2009 Resveratrol ameliorates high glucoseinduced protein synthesis in glomerular epithelial cells. Cellular Signalling $\mathbf{2 2}$ 65-70. (doi:10.1016/j.cellsig.2009.09.011)

Lisboa PC, Fagundes AT, Denolato AT, Oliveira E, Bonomo IT, Alves SB, Curty FH, Passos MC \& Moura EG 2008 Neonatal low-protein diet changes deiodinase activities and pituitary TSH response to TRH in adult rats. Experimental Biology and Medicine 233 57-63. (doi:10.3181/0705-RM-146)

Lucas A 1994 Role of nutritional programming in determining adult morbidity. Archives of Disease in Childhood 71 288-290. (doi:10.1136/adc. 71.4.288)

Macarulla MT, Alberdi G, Gómez S, Tueros I, Bald C, Rodríguez VM, Martínez JA \& Portillo MP 2009 Effects of different doses of resveratrol on body fat and serum parameters in rats fed a hypercaloric diet. Journal of Physiology and Biochemistry 65 369-376. (doi:10.1007/BF03185932)

Machado DS, Sabet A, Santiago LA, Sidhaye AR, Chiamolera MI, OrtigaCarvalho TM \& Wondisford FE 2009 A thyroid hormone receptor mutation that dissociates thyroid hormone regulation of gene expression in vivo. PNAS 106 9441-9446. (doi:10.1073/pnas.0903227106)

Marques RG, Morales MM \& Petroianu A 2009 Brazilian law for scientific use of animals. Acta Cirúrgica Brasileira 24 69-74. (doi:10.1590/S010286502009000100015)

Matthews DR, Hosker JP, Rudenski AS, Naylor BA, Treacher DF \& Turner RC 1985 Homeostasis model assessment: insulin resistance and $\beta$ cell function from fasting plasma glucose and insulin concentrations in man. Diabetologia 28 412-421. (doi:10.1007/BF00280883)

McCay CM, Crowell MF \& Maynard LA 1935 The effect of retarded growth upon the length of life span and upon the ultimate body size. Journal of Nutrition 10 63-79.

Miatello R, Vázquez M, Renna N, Cruzado M, Zumino AP \& Risler N 2005 Chronic administration of resveratrol prevents biochemical cardiovascular changes in fructose-fed rats. American Journal of Hypertension 18 864-870. (doi:10.1016/j.amjhyper.2004.12.012)

Moura EG \& Passos MC 2005 Neonatal programming of body weight regulation and energetic metabolism. Bioscience Reports 25 251-269. (doi:10.1007/s10540-005-2888-3)

Moura AS, Caldeira Filho JS, Mathias PC \& Franco de Sá CCN 1997 Insulin secretion impairment and insulin sensivity improvement in adult rats undernourished during early lactation. Research Communications in Molelcular Pathology and Pharmacology 96 180-192.

Moura EG, Lisboa PC \& Passos MC 2008 Neonatal programming of neuroimmunomodulation - role of adipocytokines and neuropeptides. Neuroimmunomodulation 15 176-188. (doi:10.1159/000153422)

Mulvihill EE \& Huff MW 2010 Antiatherogenic properties of flavonoids: implications for cardiovascular health. Canadian Journal of Cardiology 26 17A-21A.

Pacholec M, Bleasdale JE, Chrunyk B, Cunningham D, Flynn D, Garofalo RS, Griffith D, Griffor M, Loulakis P, Pabst B et al. 2010 SRT1720, SRT2183, SRT1460, and resveratrol are not direct activators of SIRT1. Journal of Biological Chemistry 285 8340-8351. (doi:10.1074/jbc.M109.088682)

Palsamy P \& Subramanian S 2008 Resveratrol, a natural phytoalexin, normalizes hyperglycemia in streptozotocin-nicotinamide induced experimental diabetic rats. Biomedicine and Pharmacotherapy 62 598-605. (doi:10.1016/j.biopha.2008.06.037)

Passos M, Ramos CF \& Moura EG 2000 Short and long term effects of malnutrition in rats during lactation on the body weight of offspring. Nutrition Research 20 1603-1612. (doi:10.1016/S0271-5317(00)00246-3) 
Passos MC, Vicente LL, Lisboa PC \& de Moura EG 2004 Absence of anorectic effect to acute peripheral leptin treatment in adult rats whose mothers were malnourished during lactation. Hormone and Metabolic Research 36 625-629. (doi:10.1055/s-2004-825927)

Pearson KJ, Baur JA, Lewis KN, Peshkin L, Price NL, Labinskyy N, Swindell WR, Kamara D, Minor RK, Perez E et al. 2008 Resveratrol delays age-related deterioration and mimics transcriptional aspects of dietary restriction without extending life span. Cell Metabolism 8 157-168. (doi:10.1016/j.cmet.2008.06.011)

Pervaiz S \& Holme AL 2009 Resveratrol: its biologic targets and functional activity. Antioxidants \& Redox Signaling 11 2851-2897. (doi:10.1089/ars. 2008.2412)

Purushotham A, Schug TT, Xu Q, Surapureddi S, Guo X \& Li X 2009 Hepatocyte-specific deletion of SIRT1 alters fatty acid metabolism and results in hepatic steatosis and inflammation. Cell Metabolism 9 327-338. (doi:10.1016/j.cmet.2009.02.006)

Radimer K, Bindewald B, Hughes J, Ervin B, Swanson C \& Picciano MF 2004 Dietary supplement use by US adults: data from the National Health and Nutrition Examination Survey, 1999-2000. American Journal of Epidemiology 160 339-349. (doi:10.1093/aje/kwh207)

Ramadori G, Gautron L, Fujikawa T, Vianna CR, Elmquist JK \& Coppari R 2009 Central administration of resveratrol improves diet-induced diabetes. Endocrinology 150 5326-5333. (doi:10.1210/en.2009-0528)

Reeves PG, Nielsen FH \& Fahey GC Jr 1993 AIN-93 purified diets for laboratory rodents: final report of the American Institute of Nutrition ad hoc writing committee on the reformulation of the AIN-76A rodent diet. Journal of Nutrition 123 1939-1951.

Rivera L, Morón R, Zarzuelo A \& Galisteo M 2009 Long-term resveratrol administration reduces metabolic disturbances and lowers blood pressure in obese Zucker rats. Biochemical Pharmacology 77 1053-1063. (doi:10.1016/ j.bcp.2008.11.027)

Rodgers JT, Lerin C, Haas W, Gygi SP, Spiegelman BM \& Puigserver P 2005 Nutrient control of glucose homeostatis through a complex of PGC- $1 \alpha$ and SIRT-1. Nature 434 113-118. (doi:10.1038/nature03354)

Sharma S, Misra CS, Arumugam S, Roy S, Shah V, Davis JA, Shirumalla RK \& Ray A 2010 Antidiabetic activity of resveratrol, a known SIRT1 activator in a genetic model for type-2 diabetes. Phytotherapy Research (In Press). (doi:10.1002/ptr.3221)

Shen X, Zheng S, Metreveli NS \& Epstein P 2006 Protection of mitochondria by over expression of MnSOD reduces diabetic cardiomyopathy. Diabetes $\mathbf{5 5}$ 798-805. (doi:10.2337/diabetes.55.03.06.db05-1039)

Sichieri R, Siqueira KS \& Moura AS 2000 Obesity and abdominal fatness associated with undernutrition early in life in a survey in Rio de Janeiro. International Journal of Obesity and Related Metabolic Disorders 24 614-618. (doi:10.1038/sj.ijo.0801205)

Singh UP, Singh N, Singh B, Hofseth LJ, Price BL, Nagarkatti M \& Nagarkatti P 2010 Resveratrol (trans-3,5, $4^{\prime}$-trihydroxystilbene) induces SIRT1 and down-regulates NF- $\kappa \mathrm{B}$ activation to abrogate DSS-induced colitis. Journal of Pharmacology and Experimental Therapeutics 332 829-839. (doi:10.1124/jpet.109.160838)

Soleas GJ, Yan J \& Goldberg DM 2001 Measurement of trans-resveratrol, $(+)$-catechin, and quercetin in rat and human blood and urine by gas chromatography with mass selective detection. Methods in Enzymology 335 130-145. (doi:10.1016/S0076-6879(01)35238-2)

Soylemez S, Sepici A \& Akar F 2009 Resveratrol supplementation gender independently improves endothelial reactivity and suppresses superoxide production in healthy rats. Cardiovascular Drugs and Therapy 23 449-458. (doi:10.1007/s10557-009-6198-z)

Spanier G, Xu H, Xia N, Tobias S, Deng S, Wojnowski L, Forstermann U \& Li H 2009 Resveratrol reduces endothelial oxidative stress by modulating the gene expression of superoxide dismutase 1 (SOD1), glutathione peroxidase 1 (GPx1) and NADPH oxidase subunit (Nox4). Journal of Physiology and Pharmacology 60 111-116.

Sulaiman M, Matta MJ, Sundaresan NR, Gupta MP, Periasamy M \& Gupta M 2010 Resveratrol, an activator of SIRT1 up-regulates sarcoplasmic calcium
ATPase and improves cardiac function in diabetic cardiomyopathy. American Journal of Physiology. Heart and Circulatory Physiology 298 H833-H843. (doi:10.1152/ajpheart.00418.2009)

Tarry-Adkins JL, Joles JA, Chen JH, Martin-Gronert MS, van der Giezen DM, Goldschmeding R, Hales CN \& Ozanne SE 2007 Protein restriction in lactation confers nephroprotective effects in the male rat and is associated with increased antioxidant expression. American Journal of Physiology. Regulatory, Integrative and Comparative Physiology 293 1259-1266. (doi:10.1152/ajpregu.00231.2007)

Tarry-Adkins JL, Martin-Gronert MS, Chen JH, Cripps RL \& Ozanne SE 2008 Maternal diet influences DNA damage, aortic telomere length, oxidative stress, and antioxidant defense capacity in rats. FASEB Journal 22 2037-2044. (doi:10.1096/fj.07-099523)

Theys N, Bouckenooghe T, Ahn MT, Remacle C \& Reusens B 2009 Maternal low-protein diet alters pancreatic islet mitochondrial function in a sex-specific manner in the adult rat. American Journal of Physiology. Regulatory, Integrative and Comparative Physiology 297 1516-1525. (doi:10.1152/ajpregu.00280.2009)

Ungvari Z, Orosz Z, Rivera A, Labinskyy N, Xiangmin Z, Olson S, Podlutsky A \& Csiszar A 2007 Resveratrol increases vascular oxidative stress resistance. American Journal of Physiology. Heart and Circulatory Physiology 292 2417-2424. (doi:10.1152/ajpheart.01258.2006)

Ungvari Z, Labinskyy N, Mukhopadhyay P, Pinto JT, Bagi Z, Ballabh P, Zhang C, Pacher P \& Csiszar A 2009 Resveratrol attenuates mitochondrial oxidative stress in coronary arterial endothelial cells. American Journal of Physiology. Heart and Circulatory Physiology 297 H1876-H1881. (doi:10. 1152/ajpheart.00375.2009)

Valenzano DR, Terzibasi E, Genade T, Cattaneo A, Domenici L \& Cellerino A 2006 Resveratrol prolongs lifespan and retards the onset of age-related markers in a short-lived vertebrate. Current Biology 16 296-300. (doi:10.1016/j.cub.2005.12.038)

Vicente LL, Moura EG, Lisboa PC, Costa AMA, Amadeu T, Mandarimde-Lacerda CA \& Passos MCF 2004 Malnutrition during lactation is associated with higher expression of leptin receptor in pituitary of the adult offspring. Nutrition 20 924-928. (doi:10.1016/j.nut.2004.06.014)

Viswanathan M, Kim SK, Berdichevsky A \& Guarente L 2005 A role for SIR2.1 regulation of ER stress response genes in determining C. elegans life span. Developmental Cell 9 605-615. (doi:10.1016/j.devcel.2005.09.017)

Vitaglione P, Sforza S, Galaverna G, Ghidini C, Caporaso N, Vescovi PP, Fogliano V \& Marchelli R 2005 Bioavailability of trans-resveratrol from red wine in humans. Molecular Nutrition \& Food Research 49 495-504. (doi:10. 1002/mnfr.200500002)

Williams LD, Burdock GA, Edwards JA, Beck M \& Bausch J 2009 Safety studies conducted on high-purity trans-resveratrol in experimental animals. Food and Chemical Toxicology 47 2170-2182. (doi:10.1016/j.fct. 2009.06.002)

Wood JG, Rogina B, Lavu S, Howitz K, Helfand SL, Tatar M \& Sinclair D 2004 Sirtuin activators mimic caloric restriction and delay ageing in metazoans. Nature $430686-689$ (Erratum in: Nature 431 107). (doi:10. 1038/nature02789)

Yu PB 1994 Cellular defenses against damage from reactive oxygen species. Physiological Reviews 74 139-162.

Zambrano E, Bautista CJ, Déas M, Martínez-Samayoa PM, GonzálezZamorano M, Ledesma H, Morales J, Larrea F \& Nathanielsz PW 2006 A low maternal protein diet during pregnancy and lactation has a sex- and window of exposure-specific effects on offspring growth and food intake, glucose metabolism and serum leptin in rat. Journal of Physiology $\mathbf{5 7 1}$ 221-230. (doi:10.1113/jphysiol.2005.100313)

\section{Received in final form 11 August 2010 \\ Accepted 23 September 2010 Made available online as an Accepted Preprint 24 September 2010}

